\title{
Comparison of lanosterol-14 alpha-demethylase (CYP51) of human and Candida albicans for inhibition by different antifungal azoles
}

\author{
Trösken, Eva R ; Adamska, Magdalena ; Arand, Michael ; Zarn, Jürg A ; Patten, Christopher ; Völkel,
} Wolfgang ; Lutz, Werner K

\begin{abstract}
Inhibition of fungal lanosterol-14 alpha-demethylase (CYP51) is the working principle of the antifungal activity of azoles used in agriculture and medicine. Inhibition of human CYP51 may result in endocrine disruption since follicular fluid-meiosis activating steroid (FF-MAS), the direct product of lanosterol demethylation, is involved in the control of meiosis. To investigate the specificity of antifungal agents for the fungal enzyme, assays to determine inhibitory potencies of 13 agricultural fungicides and 6 antimycotic drugs were established. FF-MAS product formation was measured by LC-MS/MS analysis in the incubations using lanosterol as substrate. Recombinant human enzyme (hCYP51) was available from BD Gentest. CYP51 of Candida albicans (cCYP51) was co-expressed with Candida tropicalis oxidoreductase in the baculovirus system. IC(50) values of 13 fungicides for cCYP51 ranged about sixfold (0.059-0.35 microM); for hCYP51 the range was about 30-fold (1.3-37.2 microM). The most favourable IC(50) ratio human to Candida was observed for imazalil (440-fold), while the specificity of epoxiconazole and tebuconazole for cCYP51 was only by a factor of 10. For the antimycotic drugs, the range of $\mathrm{IC}(50)$ values for cCYP51 was similar to those of fungicides (0.039-0.30 microM). For the inhibition of hCYP51, $\mathrm{IC}(50)$ values split into two classes: the newer drugs fluconazole and itraconazole showed little inhibition $(>$ or $=30$ microM $)$ while the older drugs were even more potent than the agricultural fungicides, with miconazole being the most potent (0.057 microM). No correlation was seen between the IC $(50)$ values determined for the two enzymes, indicating that a housekeeping gene can show significant diversity if inhibition is concerned. Our data indicate that fungicide residues in food are unlikely to exert a relevant inhibition of CYP51 in humans whereas systemic use of some antimycotic drugs, e.g. ketoconazole or miconazole, should be carefully considered regarding disturbance of human steroid biosynthesis.
\end{abstract}

DOI: https://doi.org/10.1016/j.tox.2006.08.007

Posted at the Zurich Open Repository and Archive, University of Zurich

ZORA URL: https://doi.org/10.5167/uzh-113576

Journal Article

Originally published at:

Trösken, Eva R; Adamska, Magdalena; Arand, Michael; Zarn, Jürg A; Patten, Christopher; Völkel, Wolfgang; Lutz, Werner K (2006). Comparison of lanosterol-14 alpha-demethylase (CYP51) of human and Candida albicans for inhibition by different antifungal azoles. Toxicology, 228(1):24-32.

DOI: https://doi.org/10.1016/j.tox.2006.08.007 


\title{
Comparison of lanosterol-14 $\alpha$-demethylase (CYP51) of human and Candida albicans for inhibition by different antifungal azoles
}

\author{
Eva R. Trösken ${ }^{\mathrm{a}, *}$, Magdalena Adamska ${ }^{\mathrm{b}}$, Michael Arand ${ }^{\mathrm{b}}$, Jürg A. Zarn ${ }^{\mathrm{c}}$, \\ Christopher Patten ${ }^{\mathrm{d}}$, Wolfgang Völkel ${ }^{\mathrm{a}}$, Werner K. Lutz ${ }^{\mathrm{a}}$ \\ a Department of Toxicology, University of Würzburg, Versbacher Str. 9, 97078 Würzburg, Germany \\ b Institute of Pharmacology and Toxicology, University of Zürich, Winterthurerstrasse 190, CH-8057 Zürich, Switzerland \\ c Swiss Federal Office of Public Health, Zürich, Switzerland \\ d BD-Gentest, BD Biosciences Discovery Labware, 6 Henshaw St., Woburn, MA 01801, USA \\ Received 24 May 2006; received in revised form 2 August 2006; accepted 3 August 2006 \\ Available online 12 August 2006
}

\begin{abstract}
Inhibition of fungal lanosterol-14 $\alpha$-demethylase (CYP51) is the working principle of the antifungal activity of azoles used in agriculture and medicine. Inhibition of human CYP51 may result in endocrine disruption since follicular fluid-meiosis activating steroid (FF-MAS), the direct product of lanosterol demethylation, is involved in the control of meiosis. To investigate the specificity of antifungal agents for the fungal enzyme, assays to determine inhibitory potencies of 13 agricultural fungicides and 6 antimycotic drugs were established. FF-MAS product formation was measured by LC-MS/MS analysis in the incubations using lanosterol as substrate. Recombinant human enzyme (hCYP51) was available from BD Gentest. CYP51 of Candida albicans (cCYP51) was co-expressed with Candida tropicalis oxidoreductase in the baculovirus system. $\mathrm{IC}_{50}$ values of 13 fungicides for cCYP51 ranged about six-fold $(0.059-0.35 \mu \mathrm{M})$; for hCYP51 the range was about 30-fold (1.3-37.2 $\mu \mathrm{M})$. The most favourable $\mathrm{IC}_{50}$ ratio human to Candida was observed for imazalil (440-fold), while the specificity of epoxiconazole and tebuconazole for cCYP51 was only by a factor of 10. For the antimycotic drugs, the range of $\mathrm{IC}_{50}$ values for cCYP51 was similar to those of fungicides $(0.039-0.30 \mu \mathrm{M})$. For the inhibition of hCYP51, IC 50 values split into two classes: the newer drugs fluconazole and itraconazole showed little inhibition $(\geq 30 \mu \mathrm{M})$ while the older drugs were even more potent than the agricultural fungicides, with miconazole being the most potent $(0.057 \mu \mathrm{M})$. No correlation was seen between the $\mathrm{IC}_{50}$ values determined for the two enzymes, indicating that a housekeeping gene can show significant diversity if inhibition is concerned. Our data indicate that fungicide residues in food are unlikely to exert a relevant inhibition of CYP51 in humans whereas systemic use of some antimycotic drugs, e.g. ketoconazole or miconazole, should be carefully considered regarding disturbance of human steroid biosynthesis.
\end{abstract}

(C) 2006 Published by Elsevier Ireland Ltd.

Keywords: Agrochemicals; Cytochrome P450 enzyme system; Fungicides; Baculovirus; Recombinant proteins; FF-MAS

\footnotetext{
* Corresponding author. Tel.: +49931 20148402; fax: +49 93120148446

E-mail address: lutz@toxi.uni-wuerzburg.de (E.R. Trösken).
}

\section{Introduction}

Cytochrome P450 monooxygenases (CYPs) form a large group of enzymes found in most organisms from bacteria to mammals and can be grouped into 281 families (Nelson, 2006; Lepesheva and Waterman, 2004). According to their function CYPs can be 
classified into enzymes metabolizing xenobiotics (e.g. CYP3A4, CYP2D6) and enzymes that are part of key biosynthetic pathways (e.g. steroid genesis), with a narrow substrate specificity (Lepesheva and Waterman, 2004). Cytochrome P450 isoenzyme 51 (CYP51/lanosterol-14 $\alpha$-demethylase) is a family of phylogenetic highly conserved monooxygenases found in mycobacteria, fungi, plants, animals and humans (Lepesheva and Waterman, 2004). In mammals and yeasts it catalyzes the three-step oxidative removal of the methyl group \#32 of lanosterol to produce follicular fluid-meiosis activating steroid (FF-MAS), an important step in sterol biosynthesis (Rozman and Waterman, 1998). In fungi, subsequent steps result in ergosterol, an essential compound of the fungal cell membrane. The working principle of azoles as fungicides relies on the inhibition of CYP51, thus fungi lack ergosterol, which leads to a collapse of the cell membrane.

In animals and humans, a downstream product of lanosterol-14 $\alpha$-demethylation is cholesterol, which is necessary for the synthesis of bile acids, mineralocorticoids, glucocorticoids and sex steroids. While cholesterol can, in principle, be supplemented with food intake, inhibition of CYP51 results in a lack of FF-MAS and its following metabolite testis-meiosis activating steroid (T-MAS). These direct products of the CYP51 reaction act as meiosis-activating steroids on ovaries and testes (Byskov et al., 2002) so that inhibition of CYP51 in human may affect the endocrine system (Zarn et al., 2003).

The ideal antifungal agent should be a potent inhibitor of fungal CYP51 while leaving the human CYP51 unaffected. Human CYP51 has been co-expressed in the baculovirus system with the respective human oxidoreductase and is available for the comparison of azoles for their inhibitory potency (Trosken et al., 2004b). CYP51 of Candida albicans has been previously cloned and expressed in yeast and bacterial expression systems (Lamb et al., 1999b; Lepesheva et al., 2001).

Several CYPs have been successfully expressed in the baculovirus system (Crespi and Miller, 1999). This system has the distinct advantages combining very high expression levels with the fidelity of an eukaryontic folding and posttranslational modification machinery. In addition two proteins can be uncertainly expressed with equally high expression levels. Cytochrome P450 enzymes are membrane bound enzymes requiring the presence of a NADPH oxidoreductase to be catalytically active. To obtain a functional enzyme the CYP can be expressed alone and reconstituted later with the oxidoreductase or the CYP is co-expressed with the oxidoreductase on the same virus construct
(Buters et al., 1994; Chen et al., 1997; Lee et al., 1995).

Up to now $C$. albicans CYP51 has not been coexpressed as a fusion protein with a respective oxidoreductase. To compare the inhibitory potency of azoles on human CYP51 and fungal CYP51, C. albicans CYP51 (Lepesheva et al., 2001) and Candida tropicalis cytochrome P450 oxidoreductase (Sutter et al., 1990) were co-expressed in the baculovirus system to obtain a functional CYP51 enzyme with a similar background as the human enzyme. $C$. tropicalis oxidoreductase was chosen as the closest available relative to the $C$. albicans oxidoreductase.

FF-MAS product formation and substrate concentration in the incubation assays was monitored directly by liquid chromatography tandem mass spectrometry (LC-MS/MS) with protein precipitation and centrifugation as only sample work-up steps (Trosken et al., 2004b).

Nineteen different antifungal agents (13 used agriculturally, 6 used in human medicine) were tested for their inhibitory potencies on human and $C$. albicans CYP51. Two azole compounds used as cytostatic drugs in human medicine, with activity based on CYP19 inhibition, were also included in the testing to verify the lack of inhibitory action on both human and fungal CYP51.

\section{Materials and methods}

\subsection{Chemicals and reagents}

Human CYP51 was a kind gift from Gentest (Trosken et al., 2004b). The pCW/C.albCYP51 vector containing the cDNA of $C$. albicans CYP51 was a kind gift from Prof. Waterman (Nashville, USA) (Lepesheva et al., 2001). The pTS1 vector containing the cDNA of $C$. tropicalis oxidoreductase was a kind gift from Dr. Sanglard (Lausanne, Switzerland) (Sutter et al., 1990). FF-MAS was a kind gift from NovoNordisk (Gentofte, Denmark). Bitertanol, cyproconazole, flusilazole, hexaconazole, imazalil, myclobutanil, penconazole, prochloraz, propiconazole, tebuconazole, triadimefon and triadimenol were from Dr. Ehrenstorfer (Augsburg, Germany). Epoxiconazole was a kind gift from the Swiss Federal Research Station (Wädenswil, Switzerland). Fluconazole was kindly provided by Pfizer $\mathrm{GmbH}$ (Karlsruhe, Germany). Clotrimazole was from Bufa (Uitgeest, The Netherlands). Fadrozole and letrozole were kind gifts from Novartis Pharma AG (Basel, Switzerland). Bifonazole, ketoconazole, itraconazole, miconazole and all other chemicals were of the highest grade available from Sigma/Fluka (Taufkirchen, Germany). Restriction endonucleases and other modifying enzymes were purchased from New England Biolabs (Beverly, USA). Bac-to-Bac ${ }^{\circledR}$ Baculovirus Expression System, pFastBac ${ }^{\mathrm{TM}}$ Dual Vector Kit, Zero Blunt $^{\circledR}$ TOPO ${ }^{\circledR}$ PCR Cloning Kit, Cellfectin ${ }^{\circledR}$ Reagent, MAX 
Efficiency ${ }^{\circledR}$ DH10Bac ${ }^{\mathrm{TM}}$ Competent $E$. coli, M13 reverse and M13 forward primer were from Invitrogen (Karlsruhe, Germany). Reagents for bacterial growth were from Carl Roth (Karlsruhe, Germany). The E. coli strain DH10Bac ${ }^{\mathrm{TM}}$ was from Invitrogen (Karlsruhe, Germany). SF9 insect cell culture medium SF 3 Baculo Express ICM and TNM-FH Insect Medium were from Biozol (Munich, Germany) and BD Biosciences (Whoburn, USA), respectively. Fetal calf serum was from PAA Laboratories (Cölbe, Germany). DNA-isolation kits were from Quiagen (Hilden, Germany).

\subsection{Cloning and construction of expression vectors}

The $C$. albicans CYP51 cDNA (Lepesheva et al., 2001) was isolated from the pCW/C.albCYP51 vector after restriction with BamHI and HindIII. The fragment was inserted under control of the polyhedrin promoter into the BamHI and HindIII digested $\mathrm{pFastBac}{ }^{\mathrm{TM}}$ Dual Vector. The $C$. tropicalis oxidoreductase cDNA (Sutter et al., 1990) was amplified from the pTS1 vector by PCR. The upstream primer 5'-ATC GCT CGA GTC ATG GCA TTA GAT AAG-3' corresponding to the $C$. tropicalis oxidoreductase sequence from 554 to $569 \mathrm{bp}$, contained an XhoI site (underlined). The downstream primer 5'-TAA TCA GCT GTT CAT ATT TTC CTT ACC AG-3' from 11 to $30 \mathrm{bp}$ is complementary to $C$. tropicalis oxidoreductase cDNA sequence from 2593 to $2612 \mathrm{bp}$. A PvuII site (underlined) was introduced. The resulting PCR product was isolated from agarose gel, cloned into the Zero Blunt ${ }^{\circledR}$ TOPO $^{\circledR}$ PCR Cloning vector and sequenced, no mutations were found. The vector containing the PCR product was digested by $B s p H I$, $P v u \mathrm{II}$ and $X h o \mathrm{I}$. The DNA fragment was cloned into the $P v u \mathrm{II}$ and XhoI digested pFastBac ${ }^{\mathrm{TM}}$ Dual Vector, harbouring the cDNA of $C$. albicans CYP51. The $C$. tropicalis oxidoreductase insert is under control of the p10 promoter. Competent MAX Efficiency ${ }^{\circledR}$ E. coli cells were transformed with the recombinant plasmid and colonies containing the recombinant bacmid were grown according to the Bac-to-Bac ${ }^{\circledR}$ Baculovirus Expression System instructions. The resulting bacmid DNA was isolated using a DNA-isolation kit. Correct insertion of the DNA construct into the bacmid DNA was controlled by PCR with M13 forward and M13 reverse primer according to the manufacturers' instructions.

\subsection{Expression and preparation of membranes}

Spodoptera frugiperda (SF9) cells were grown in SF 3 Baculo Express ICM Cell Culture Medium at room temperature $\left(25^{\circ} \mathrm{C}\right)$ and the transfection of the bacmid DNA with Cellfectin ${ }^{\circledR}$ was performed according to the Bac-to-Bac ${ }^{\circledR}$ manual. Two sequential infection rounds produced baculovirus stock with a titer of $2 \times 10^{7}$ plaque forming units $(\mathrm{pfu}) / \mathrm{mL}$ as determined by plaque assay. For protein production cells were grown in $500 \mathrm{~mL}$ SF 3 Baculo Express ICM Cell Culture Medium supplemented with $10 \%$ fetal calf serum (FCS) to a density of $3.4-4 \times 10^{6}$ cells $/ \mathrm{mL}(500 \mathrm{~mL})$ in $1800 \mathrm{~mL}$ Fernbachflasks. Cells were infected at $0.01 \mathrm{pfu} / \mathrm{mL}$ and medium was supplemented with $4 \mu \mathrm{g} / \mathrm{mL}$ hemin from a $2 \mathrm{mg} / \mathrm{mL}$ hemin stock solution prepared in $0.4 \mathrm{M} \mathrm{NaOH} /$ ethanol $(1: 1)$ (Gonzalez et al., 1991). The infection was allowed to proceed until $30-50 \%$ of the cells stained with the trypan blue dye exclusion test and cells showed signs of late to very late infection. Cells were harvested by centrifugation, washed, resuspended in $0.05 \mathrm{M}$ potassium phosphate buffer $\mathrm{pH} 7.4$ supplemented with $0.5 \mathrm{M}$ sucrose and stored at $-70^{\circ} \mathrm{C}$ until further use. Cells were homogenized with a Sartorius Potter S Homogeniser apparatus (Goettingen, Germany) and cell membranes were prepared by centrifugation at $10,000 \times g$ and $100,000 \times g$. Membrane preparations $(10,000 \times g)$ of four insect cell preparations were pooled and used for incubation procedures of $C$. albicans CYP51.

\subsection{Analysis of membranes}

The $10,000 \times g$ membrane fractions were used for the inhibition studies because they contained more than $80 \%$ of the total enzyme activity. About $10 \%$ was found in the $100,000 \times g$ fraction and another $10 \%$ in the supernatant of the microsomal preparations. Protein concentration of the microsomal preparations was determined following the method of Bradford utilizing bovine serum albumin as reference. Cytochrome P450 content of the microsomal preparations was determined by CO difference absorbance spectra according to Omura and Sato (1964).

\subsection{CYP51 incubation assays}

Stock solutions of lanosterol $1 \mathrm{mM}$ and Triton X 100 $16 \mathrm{mg} / \mathrm{mL}$ were prepared in isopropanol. Stock solutions and dilution series of azoles were prepared in ethanol, except for ketoconazole, itraconazole and miconazole where dimethylsulfoxide was used. A master mix containing $975 \mu \mathrm{L}$ of $0.1 \mathrm{M}$ potassium phosphate buffer ( $\mathrm{pH} 7.4), 40 \mu \mathrm{L}$ of a $50 \mathrm{mM}$ $\mathrm{NADP}^{+}$solution, $75 \mu \mathrm{L}$ of a $66 \mathrm{mM}$ magnesium chloride solution, $50 \mu \mathrm{L}$ of a $100 \mathrm{mM}$ glucose-6-phosphate solution and $7 \mu \mathrm{L}$ of a $0.1 \mathrm{U} / \mu \mathrm{L}$ glucose- 6 -phosphate dehydrogenase solution was prepared. Seventy-six microliters of this solution were mixed with $4 \mu \mathrm{L}$ of a 1:1 mix of lanosterol and Triton $\mathrm{X} 100$ solution and $1 \mu \mathrm{L}$ of azole dilution. The reaction mixture was preincubated for $5 \mathrm{~min}$ at $37^{\circ} \mathrm{C}$ and the reaction was started by addition of $20 \mu \mathrm{L}$ of $C$. albicans CYP51. After $40 \mathrm{~min} 100 \mu \mathrm{L}$ of isopropanol containing internal standard $d_{6}$ cholesterol $(5 \mu \mathrm{M})$ were added to stop the reaction. Protein was removed by centrifugation at $15,000 \times g$ for $10 \mathrm{~min}$. The supernatant was transferred to low volume insert sample-vials and $10 \mu \mathrm{L}$ were injected into the HPLC interface and analyzed by LC-MS/MS. The LC-MS/MS analysis was performed as described previously (Trosken et al., 2004b, 2005). For the determination of $K_{\mathrm{m}}$ and $V_{\max }$ the described incubation assay for $C$. albicans CYP51 was performed with dilution series of lanosterol resulting in an inter assay substrate concentration ranging from 1 to $50 \mu \mathrm{M}$. The amount of isopropanol in the incubation assay was kept constant. 
Inhibition assays with human CYP51 were performed similar to the $C$. albicans CYP51 assay. For details see Trosken et al. (2004b).

\subsection{Data analysis}

The area of the FF-MAS peak was normalized by the peak area of the internal standard. The resulting relative area was plotted against the $\log _{10}$ of the concentration of azole. The data were analyzed as described (Trosken et al., 2004a). Four parameters were estimated by fitting the two replicate area data sets to a probit curve: the FF-MAS relative area at azole concentration 0 and $\infty$, the relative area at half maximum inhibition, and the slope of the probit curve. Statistical analysis was performed by a nonlinear mixed-effects model fit by maximum likelihood run on the statistics software "R" (http://www.r-project.org). A random error was attributed to the FF-MAS relative area at azole concentration 0 , to account for differences between the duplicates for the asymptotic background measure.

In order to generate a complete log-normal inhibition curve for the statistical analysis, one theoretical high-dose data point was added with full inhibition (zero-product formation) when solubility limits did not allow experimental determination of a second zero-product data point. In the human CYP51 assay for fluconazole, itraconazole, fadrozole and letrozole no $\mathrm{IC}_{50}$ values could be calculated due to the low inhibitory potency and the limited solubility.

Kinetic parameters $K_{\mathrm{m}}$ and $V_{\max }$ were determined by nonlinear regression analysis according to Kakkar et al. (1999, Eq. (2)). Spearman rank correlation was calculated using the free statistics software "R" (http://www.r-project.org).

\section{Results}

\subsection{Analytical procedures}

FF-MAS product formation and substrate concentration in the incubation assays was monitored directly by liquid chromatography tandem mass spectrometry (LC-MS/MS) with protein precipitation and centrifugation as only sample work-up steps (Trosken et al., 2004b). Fig. 1 depicts a LC-MS/MS chromatogram with FF-MAS, the product of the CYP51 reaction with lanosterol, eluting at $8.6 \mathrm{~min}$, internal standard $d_{6}$-cholesterol eluting at $8.8 \mathrm{~min}$ and the substrate lanosterol eluting at $9.1 \mathrm{~min}$. Complete resolution of the signals was not required due to the double mass-selective analysis. In comparison to the established methods of measuring product formation of CYP51, gas chromatography mass spectrometry or release of radiolabelled formic acid, the utilized method has the distinct advantages of minimal sample preparation and short HPLC run times. No extraction or derivatization steps are necessary for the analytical method, thus artefact formation is negligible.

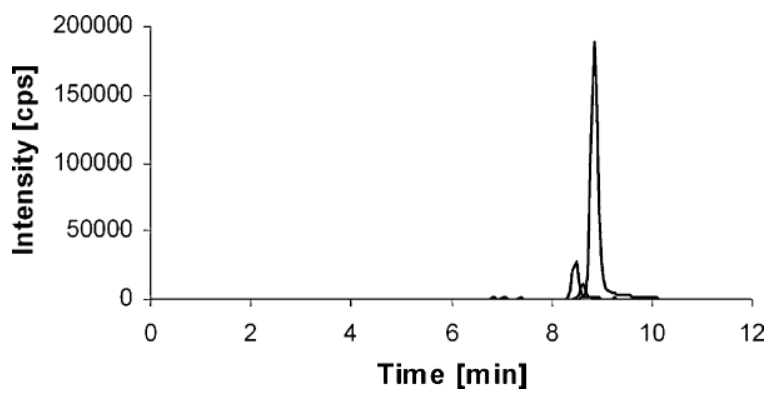

Fig. 1. LC-MS/MS Chromatogram of an incubation of Candida albicans CYP51 with lanosterol as substrate. The reaction product FFMAS is detected at $8.6 \mathrm{~min}$ retention time, the internal standard $d_{6}$ cholesterol at $8.8 \mathrm{~min}$ and the substrate lanosterol at $9.1 \mathrm{~min}$.

\subsection{Human CYP51}

The P450 contents of human CYP51 supersomes had been determined to be $20 \mu \mathrm{M}$ equivalent to $0.4 \mathrm{nmol} \mathrm{P} 450 / \mathrm{mg}$ protein (Trosken et al., 2004b), resulting in an assay concentration of $0.1 \mu \mathrm{M}$ equivalents to 8 pmol P450. Protein concentration of the membranes was determined to be $50 \mu \mathrm{g} / \mu \mathrm{L}$, resulting in an assay protein concentration of $0.3 \mu \mathrm{g} / \mu \mathrm{L}$. The concentration of organic solvents in the assay was $5 \%$. Product formation was linear from 10 to $40 \mathrm{~min}$ and from 4 to 16 pmol P450 enzyme (data not shown). $K_{\mathrm{m}}$ and $V_{\max }$ of human CYP51 were determined to be $1.7 \pm 0.7 \mu \mathrm{M}$ and $0.3 \pm 0.04 \mathrm{pmol} / \mathrm{min} \times \mathrm{pmol} \mathrm{P} 450$, respectively. The substrate concentration for the determination of $\mathrm{IC}_{50}$ values was chosen to be $15 \mu \mathrm{M}$ equivalent to eight times $K_{\mathrm{m}}$. In the absence of inhibitor, $1 \%$ of the total substrate amount was metabolized within $40 \mathrm{~min}$.

\subsection{C. albicans CYP51 assay}

Protein concentration of the membranes was $50 \mu \mathrm{g} / \mu \mathrm{L}$, the protein concentration used in the assay was $10 \mu \mathrm{g} / \mu \mathrm{L}$. The concentration of organic solvents in the assay was 5\%. The $\mathrm{P} 450$ content of the membranes was determined to be $1 \mu \mathrm{M}$ equivalent to $0.02 \mathrm{nmol} \mathrm{P} 450 / \mathrm{mg}$ protein, the enzyme concentration in the assay was $0.2 \mu \mathrm{M}$ equivalents to $20 \mathrm{pmol}$ P450 enzyme. The absorption maxima of the carbon monoxide-bound form were located at $450 \mathrm{~nm}$ with no absorption at $420 \mathrm{~nm}$, indicating a fully functional enzyme complex (data not shown).

Product formation was proportional to enzyme amount from 5 to 40 pmol (Fig. 2) but levelled off with time (Fig. 3). A possible explanation could be the deterioration of the enzyme in the incubation mixture. Despite the nonlinear product formation within 40 min we used this incubation period for the determination of the $\mathrm{IC}_{50}$ 


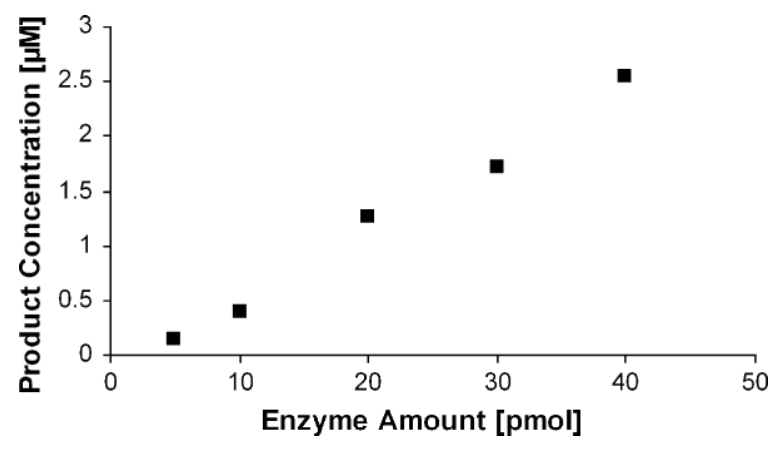

Fig. 2. FF-MAS product formation as a function of the enzyme amount (pmol) of C. albicans CYP51 (lanosterol-14 $\alpha$-demethylase) in the incubation assay.

values because the time course was reproducible and since higher levels of product reduce the standard error of the mass spectrometric signal.

$K_{\mathrm{m}}$ and $V_{\max }$ of $C$. albicans CYP51 at $40 \mathrm{~min}$ incubation time were determined to be $7.4 \pm 0.86 \mu \mathrm{M}$ and $\quad 0.46 \pm 0.019 \mathrm{pmol} / \mathrm{min} \times \mathrm{pmol} \mathrm{P} 450, \quad$ respectively. $V_{\max }$ at $10 \mathrm{~min}$ incubation time was $1.06 \pm 0.08 \mathrm{pmol} / \mathrm{min} \times \mathrm{pmol}$ P450. Substrate con-

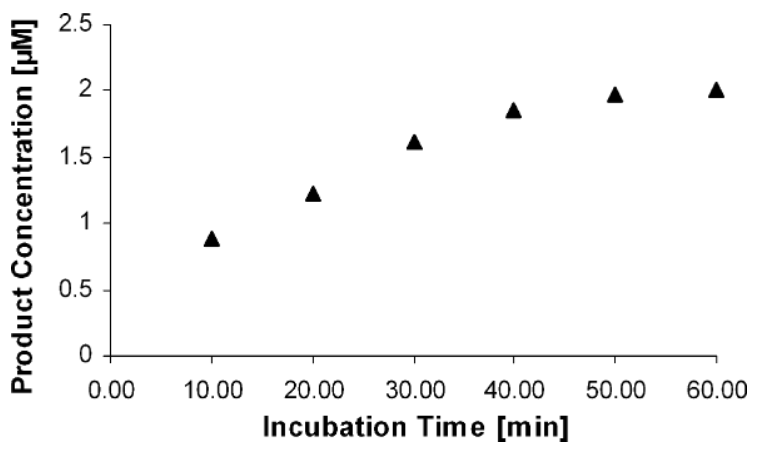

Fig. 3. FF-MAS product formation as a function of time of incubation of C. albicans CYP51 (lanosterol-14 $\alpha$-demethylase) membranes with lanosterol substrate.

centration for the determination of $\mathrm{IC}_{50}$ values was chosen to be $20 \mu \mathrm{M}$, equivalent to approximately 2.7 times $K_{\mathrm{m}}$. Lanosterol concentrations could not be kept at eight times $K_{\mathrm{m}}$ due to solubility problems of lanosterol in higher concentrations and effects on the substrate turn-over. In the absence of inhibitors, approximately $20 \%$ of the substrate added was metabolized to FF-MAS within $40 \mathrm{~min}$.

Table 1

Inhibitory potency of azoles on human lanosterol-14 $\alpha$-demethylase (hCYP51) and CYP51 of Candida albicans (cCYP51)

\begin{tabular}{|c|c|c|c|c|c|}
\hline Azole & $\mathrm{IC}_{50}$ hCYP51 & S.E. & $\mathrm{IC}_{50} \mathrm{cCYP51}$ & S.E. & Ratio $(\mathrm{h} / \mathrm{c})$ \\
\hline \multicolumn{6}{|l|}{ Fungicides } \\
\hline Bitertanol & 1.30 & 1.29 & 0.059 & 1.22 & 22 \\
\hline Cyproconazole & $22.8^{\mathrm{a}}$ & 1.62 & 0.10 & 1.16 & 228 \\
\hline Epoxiconazole & 1.95 & 1.51 & 0.22 & 1.13 & 9 \\
\hline Flusilazole & 3.36 & 1.58 & 0.085 & 1.22 & 40 \\
\hline Hexaconazole & $15.6^{\mathrm{a}}$ & 1.5 & 0.066 & 1.28 & 236 \\
\hline Imazalil & 36.1 & 1.95 & 0.082 & 1.10 & 440 \\
\hline Myclobutanil & $29.0^{\mathrm{a}}$ & 1.57 & 0.14 & 1.16 & 207 \\
\hline Penconazole & 19.3 & 1.40 & 0.076 & 1.15 & 254 \\
\hline Prochloraz & 5.00 & 1.23 & 0.098 & 1.25 & 51 \\
\hline Propiconazole & 8.25 & 1.41 & 0.15 & 1.14 & 55 \\
\hline Tebuconazole & 3.61 & 2.08 & 0.35 & 1.40 & 10 \\
\hline Triadimefon & 9.95 & 1.62 & 0.13 & 1.30 & 77 \\
\hline Triadimenol & $37.2^{\mathrm{a}}$ & 1.36 & 0.33 & 1.27 & 113 \\
\hline \multicolumn{6}{|l|}{ Antifungal drugs } \\
\hline Bifonazole & 0.80 & 1.80 & 0.30 & 1.13 & 3 \\
\hline Clotrimazole & 0.85 & 1.47 & 0.091 & 1.12 & 9 \\
\hline Fluconazole & $>30(23 \% \text { inhibition })^{\mathrm{b}}$ & & 0.051 & 1.09 & 588 \\
\hline Itraconazole & $\approx 30(53 \% \text { inhibition })^{\mathrm{b}}$ & & 0.039 & 1.13 & 769 \\
\hline Ketoconazole & 0.43 & 1.24 & 0.064 & 1.08 & 7 \\
\hline Miconazole & 0.057 & 1.24 & 0.072 & 1.09 & 0.8 \\
\hline \multicolumn{6}{|l|}{ Cytostatic drugs } \\
\hline Fadrozole & $\approx 100\left(54 \%{\text { inhibition })^{\mathrm{b}}}^{\mathrm{b}}\right.$ & & 32.2 & 1.41 & \\
\hline Letrozole & $>100\left(_{(11 \%}{\text { inhibition })^{b}}^{b}\right.$ & & 13.3 & 1.26 & \\
\hline
\end{tabular}

$\mathrm{IC}_{50}$ values are given in $(\mu \mathrm{M})$ concentrations. A geometric standard error is given $(\times / \div)$ because estimates of $\mathrm{IC}_{50}$ values and standard errors were estimated on the basis of $\log$ (concentration).

a One theoretical high-dose/zero-product point added for parameter estimation.

b No full sigmoid curve available due to limited solubility. 


\subsection{IC 50 values}

Table 1 displays the $\mathrm{IC}_{50}$ values with geometric standard errors determined for human CYP51 and C. albicans CYP51. The inhibitory potencies of azole fungicides on human CYP51 ranged approximately 30-fold, from 1.30 to $37.2 \mu \mathrm{M}$. The most potent compounds are bitertanol and epoxiconazole; the least potent are imazalil and triadimenol. The $\mathrm{IC}_{50}$ values of the antifungal drugs showed a wider span (500-fold) from $0.057 \mu \mathrm{M}$ (miconazole) to $>30 \mu \mathrm{M}$ (fluconazole). Miconazole was the most potent of all azoles tested. Four of the six antifungal drugs (miconazole, bifonazole, clotrimazole and ketoconazole) were more potent than the most potent fungicide (bitertanol). These are all imidazole compounds and the older compounds on the market compared to the two newer triazole compounds, fluconazole and itraconazole. The two cytostatic drugs tested display only low inhibitory potency $(\geq 100 \mu \mathrm{M})$. Geometric standard errors ranged between 1.23 and 2.08. This is acceptable in relation to the differences of the $\mathrm{IC}_{50}$ values between the azoles.

The inhibitory potency of the fungicides on $C$. albicans CYP51 ranged only six-fold, from 0.059 to $0.35 \mu \mathrm{M}$. The most potent compounds were bitertanol and hexaconazole; the less potent compounds were tebuconazole and triadimenol. The $\mathrm{IC}_{50}$ values of the antifungal drugs also showed a small range of 8 from $0.039 \mu \mathrm{M}$ (itraconazole) to $0.3 \mu \mathrm{M}$ (bifonazole). Itraconazole was the most potent of all azoles tested.

The two cytostatic drugs displayed a 30-100-fold lower inhibitory potency against $C$. albicans CYP51. The geometric standard errors were smaller in general than with hCYP51, ranging between 1.08 and 1.41.

The $\mathrm{IC}_{50}$ values determined for hCYP51 and cCYP51 do not correlate with each other (see Fig. 4) and they do not correlate with $\log p$ values of the azole compounds.

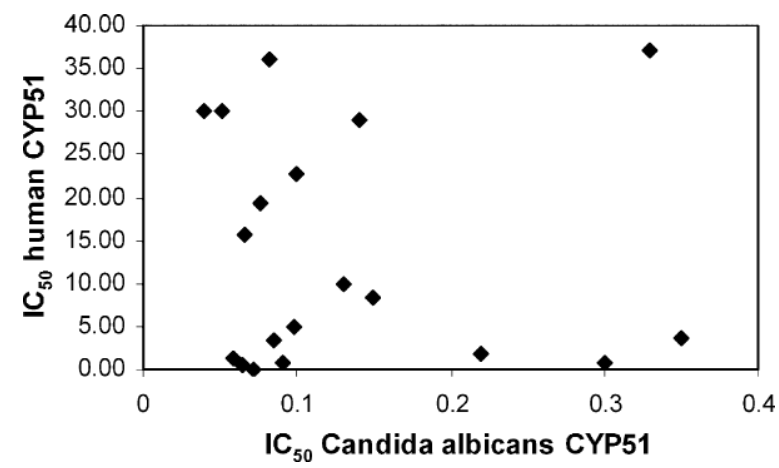

Fig. 4. Plot of $\mathrm{IC}_{50}$ values for antifungal azole compounds determined for human CYP51 (lanosterol-14 $\alpha$-demethylase; $y$-axis) and CYP51 of $C$. albicans ( $x$-axis). $\mathrm{IC}_{50}$ values are given in $\mu \mathrm{M}$ concentrations.
The Spearman rank correlation coefficient $\rho$ was -0.39 with a $p$ of 0.12 for the correlation of hCYP51 and $\log p$ values. For the correlation of cCYP51 and $\log p$ values the correlation coefficient $\rho$ was -0.31 with a $p$ of 0.17 . The $\log p$ (or partition coefficient) describes the differential solubility of a compound in octanol and water and is a measure of the hydrophobicity/hydrophilicity of a substance.

A ratio of the $\mathrm{IC}_{50}$ values determined for the human enzyme divided by the $\mathrm{IC}_{50}$ determined for the $C$. albicans enzyme is given in the last column of Table 1 . The values for the ratio range from 0.8 (miconazole) to 769 (itraconazole). A small ratio indicates an unfavourable, small difference between the inhibitory potency for the fungal CYP51, compared to the human enzyme, i.e. low selectivity. This is the case for the agriculturally used fungicides epoxiconazole and tebuconazole and for the antifungal drugs bifonazole, clotrimazole, ketoconazole and miconazole.

The larger the ratio, the better the selectivity for the fungal variant of the enzyme. Such a favourable ratio was found for the fungicides cyproconazole, hexaconazole, imazalil, myclobutanil and penconazole. Of the antifungal drugs, only fluconazole and itraconazole showed such a desirable high ratio.

\section{Discussion}

C. albicans CYP51 (Lepesheva et al., 2001) and $C$. tropicalis cytochrome $\mathrm{P} 450$ oxidoreductase (Sutter et al., 1990) were co-expressed in the baculovirus system to obtain a functional enzyme complex with a similar background as the human enzyme available from BD Gentest. Thus the inhibitory potencies of azoles on human and fungal CYP51 could be determined in equivalent systems.

C. albicans CYP51 has been expressed before in Saccharomyces cerevisiae, purified on chromatographic columns and reconstituted by Lamb et al. (1997b, 1999a,b). The $K_{\mathrm{m}}$ values and respective $V_{\max }$ values are given in Table 2 and are compared to the values determined for the C. albicans CYP51-C. tropicalis oxidoreductase construct. The $K_{\mathrm{m}}$ values reported are three to four times higher compared to the value determined for the construct described above. $K_{\mathrm{m}}$ is a measure of the affinity of a substrate to an enzyme and is independent of the enzyme amount used.The difference between the literature value and the one described above can be in part explained by the fact that Lamb et al. used a different expression system namely $S$. cerevisiae. C. albicans CYP51 was expressed alone and was later reconstituted with a rabbit oxidoreductase. Additionally the 
Table 2

Kinetic parameters $K_{\mathrm{m}}$ and $V_{\max }$ of heterologously expressed C. albicans lanosterol-14 $\alpha$-demethylase (cCYP51)

\begin{tabular}{|c|c|c|}
\hline & $K_{\mathrm{m}}(\mu \mathrm{M})$ & $V_{\max }$ \\
\hline Our values & 7.4 & $\begin{array}{l}0.46 \mathrm{~mol} \text { product } / \\
\mathrm{min} \times \mathrm{mol} \mathrm{P} 450\end{array}$ \\
\hline Lamb et al. $(1999 b)^{a}$ & 20.8 & $\begin{array}{l}0.15 \text { mol product/ } \\
\text { min } \times \text { mol } \mathrm{P} 450\end{array}$ \\
\hline Lamb et al. $(1999 a)^{b}$ & 21 & $\begin{array}{l}0.24 \pm 0.04 \text { mol product/ } \\
\min \times \text { mol } \mathrm{P} 450\end{array}$ \\
\hline Lamb et al. (1997b) ${ }^{\mathrm{a}}$ & 29.4 & $\begin{array}{l}0.15 \mathrm{~mol} \text { substrate converted } / \\
\mathrm{min} \times \mathrm{mol} \mathrm{P} 450\end{array}$ \\
\hline
\end{tabular}

Comparison of our values (crude membranes) with literature values for purified enzyme.

a Catalytic activity was achieved by reconstitution of purified enzyme with rabbit NADPH oxidoreductase (Lamb et al., 1997b, 1999b).

${ }^{\mathrm{b}}$ Catalytic activity was achieved by reconstitution of purified enzyme with yeast cytochrome $b_{5}$ and NADH cytochrome $b_{5}$ reductase or with yeast oxidoreductase (Lamb et al., 1999a).

non-purified enzyme shows a higher affinity to its substrate than the purified ones described in the literature. In the living organism cytochrome P450 enzymes and the respective oxidoreductase form a complex anchored in the cell membrane. By purifying the enzyme it is removed from its "natural" environment. This could have an influence on the enzyme conformation and thus on its substrate affinity indicated by the higher $K_{\mathrm{m}}$ values.

The $V_{\max }$ value determined for the described nonpurified enzyme ( $40 \mathrm{~min}$ incubation time) is not comparable to one of those reported in the literature. The literature values are two to three times lower. Differences could be explained by the fact that different analytical methods were used to monitor product formation and that for the lowest $V_{\max }$ value reported substrate turn-over was determined rather than product formation.
Table 4

Comparison of our $\mathrm{IC}_{50}$ values for human lanosterol-14 $\alpha$-demethylase (hCYP51) with those reported in the literature

\begin{tabular}{lll}
\hline Substance & This manuscript & Lamb et al. (1999b) \\
\hline Itraconazole & $\approx 30(53 \%$ inhibition $)$ & 0.61 \\
Ketoconazole & 0.43 & 0.58
\end{tabular}

a Purified human CYP51, formic acid release assay (Lamb et al., 1999b).

Further explanations for the differences found both for $K_{\mathrm{m}}$ and $V_{\max }$ could be the different analytical procedures used to calculate both constants (nonlinear model versus double-inverse linear Lineweaver-Burk plots) and the uncertainty about the error of two of the three literature values.

Human CYP51 has also been heterologously expressed in yeast and purified (Lamb et al., 1999b). Catalytic activity was reconstituted by addition of rabbit NADPH oxidoreductase and $K_{\mathrm{m}}$ and $V_{\max }$ were determined to be $29.4 \mu \mathrm{M}$ and $0.474 \mathrm{pmol}$ product/ min $\times$ pmol P450. Differences to the human enzyme used in this manuscript can be explained by the same arguments brought forward for the differences between the $C$. albicans CYP51 described and literature values, namely a different expression system, reconstitution versus native enzyme and co-expression.

\subsection{Comparison with literature $I_{50}$ values}

Lamb et al. (1999b) determined IC $_{50}$ values for ketoconazole and itraconazole with a formic acid release assay. They found a less than 10 -fold difference between the fungal and the human enzyme (Tables 3 and 4). The values for ketoconazole could be reproduced here on both enzymes. For itraconazole, we found a similar $\mathrm{IC}_{50}$

Table 3

Comparison of our $\mathrm{IC}_{50}$ values for $C$. albicans lanosterol-14 $\alpha$-demethylase (cCYP51) with those reported in the literature

\begin{tabular}{|c|c|c|c|c|c|}
\hline Substance & This manuscript & $\begin{array}{l}\text { Lamb et al. } \\
(1999 b)^{\mathrm{a}}\end{array}$ & $\begin{array}{l}\text { Lamb et al. } \\
(2000)^{\mathrm{b}}\end{array}$ & $\begin{array}{l}\text { Lamb et al. } \\
(1997 a)^{b}\end{array}$ & $\begin{array}{l}\text { Vanden Bossche et al. (1987), Vanden } \\
\text { Bossche and Koymans }(1998)^{\mathrm{c}}\end{array}$ \\
\hline Imazalil & 0.082 & & & & 0.05 \\
\hline Penconazole & 0.076 & & & & 0.019 \\
\hline Propiconazole & 0.15 & & & & 0.061 \\
\hline Bifonazole & 0.30 & & & & 1.170 \\
\hline Clotrimazole & 0.091 & & & & 0.036 \\
\hline Fluconazole & 0.051 & & & 0.053 & 0.249 \\
\hline Itraconazole & 0.039 & 0.08 & 0.0076 & & 0.031 \\
\hline Ketoconazole & 0.064 & 0.06 & 0.008 & 0.006 & 0.03 \\
\hline Miconazole & 0.072 & & & & 0.076 \\
\hline
\end{tabular}

\footnotetext{
a Purified C. albicans CYP51, formic acid release assay (Lamb et al., 1999b).

b Cell free biosynthesis of ergosterol from $\left[2-{ }^{14} \mathrm{C}\right]$ mevalonate with C. albicans (Lamb et al., 1997a, 2000).

c Inhibition of CO-binding to central heme iron using C. albicans membranes (Vanden Bossche et al., 1987; Vanden Bossche and Koymans, 1998).
} 
value for $C$. albicans, while the human variant of the enzyme showed a much higher $\mathrm{IC}_{50}$ value $(30 \mu \mathrm{M}$ versus $0.61 \mu \mathrm{M}$ by Lamb et al. (1999b)). No explanation can be given for this difference.

Table 3 includes literature data based on the use of $\left[2-{ }^{14} \mathrm{C}\right]$ mevalonate as substrate. This compound is a precursor of lanosterol that is synthesized in situ in the assay. $\mathrm{IC}_{50}$ values of $0.053 \mu \mathrm{M}$ for fluconazole, $0.0076 \mu \mathrm{M}$ for itraconazole and $0.008-0.006 \mu \mathrm{M}$ for ketoconazole were found (Lamb et al., 1997a, 2000). The values for itraconazole and ketoconazole are a factor of 5-10 below those reported by the same group using the formic acid release assay and those reported in this manuscript. An explanation could be that the lanosterol substrate concentration is not known in the $\left[2-{ }^{14} \mathrm{C}\right]$ mevalonate assay. However, $\mathrm{IC}_{50}$ values are dependent on the substrate concentration. Another interpretation of the difference in $\mathrm{IC}_{50}$ values is that the azoles inhibited not only CYP51 but also enzymes necessary for the production of lanosterol from mevalonate.

Vanden Bossche et al. reported $\mathrm{IC}_{50}$ values for a variety of azole compounds using membranes isolated from C. albicans (Table 3) (Vanden Bossche et al., 1987; Vanden Bossche and Koymans, 1998). Numerical values fit well to the ones determined here for some examples, e.g. imazalil, itraconazole, ketoconazole and miconazole. For others the difference to our values and those of Lamb's was by a factor of up to 5 (fluconazole). The inhibitory potency was assessed by the inhibition of CO-binding to the central heme iron of CYP51. It is questionable whether this assay can fully assess the inhibitory potency of mixed-type or non-competitive inhibitors, which could explain the observed differences.

Lamb et al. postulate that in crude membrane fractions of rat or human liver azole compounds are scavenged by other microsomal enzymes present. Thus higher concentrations of inhibitor are necessary and higher $\mathrm{IC}_{50}$ values result. Trzaskos and Henry reported already in 1989 that the sensitivity of rat CYP51 towards flusilazole is enhanced when the enzyme is partially purified from rat hepatic microsomes (Trzaskos and Henry, 1989). By expressing both human CYP51 and C. albicans CYP51 in the same system a similar protein background is present in both incubation assays. Furthermore, the level of cytochrome P450 enzymes expressed in insect cell lines is much lower than in mammalian liver microsomes. Scavenging of azole inhibitor by other cytochrome P450 enzymes was therefore less of a problem in our assays.

The assays established here allowed for an optimal comparison of inhibitory potencies of azole compounds towards human and fungal CYP51. For a number of com- pounds, e.g. epoxiconazole, tebuconazole, bifonazole, clotrimazole, ketoconazole and miconazole, the difference between the inhibition of human CYP51 and fungal CYP51 is smaller than by a factor of 10. For imazalil, fluconazole and itraconazole, on the other hand, the difference between the inhibition of fungal and human enzyme is by more than a factor of 400 , indicating high specificity for the fungal enzyme compared to the human analogue. This is a desirable feature for all antifungal azole compounds since production of FF-MAS and TMAS in humans should not be inhibited.

\section{Acknowledgements}

The authors greatly acknowledge the generous provision of material by Prof. M. Waterman of the Department of Biochemistry, Vanderbilt University School of Medicine, Nashville, Tennessee and by Dr. D. Sanglard of the Institute of Microbiology, University Hospital of Lausanne (CHUV), Switzerland. Further R.W. Lutz of the Seminar for Statistics, Swiss Federal Institute of Technology, Zurich, Switzerland for the development of the statistical function to calculate $K_{\mathrm{m}}$ and $V_{\max }$. This work was supported by the Swiss Federal Office of Public Health (grant 04.002267).

\section{References}

Buters, J.T., Korzekwa, K.R., Kunze, K.L., Omata, Y., Hardwick, J.P., Gonzalez, F.J., 1994. cDNA-directed expression of human cytochrome P450 CYP3A4 using baculovirus. Drug Metab. Dispos. 22, 688-692.

Byskov, A.G., Andersen, C.Y., Leonardsen, L., 2002. Role of meiosis activating sterols, MAS, in induced oocyte maturation. Mol. Cell. Endocrinol. 187, 189-196.

Chen, L., Buters, J.T., Hardwick, J.P., Tamura, S., Penman, B.W., Gonzalez, F.J., Crespi, C.L., 1997. Coexpression of cytochrome P4502A6 and human NADPH-P450 oxidoreductase in the baculovirus system. Drug Metab. Dispos. 25, 399-405.

Crespi, C.L., Miller, V.P., 1999. The use of heterologously expressed drug metabolizing enzymes-state of the art and prospects for the future. Pharmacol. Ther. 84, 121-131.

Gonzalez, F.J., Kimura, S., Tamura, S., Gelboin, H.V., 1991. Expression of mammalian cytochrome P450 using baculovirus. Meth. Enzymol. 206, 93-99.

Kakkar, T., Boxenbaum, H., Mayersohn, M., 1999. Estimation of Ki in a competitive enzyme-inhibition model: comparisons among three methods of data analysis. Drug Metab. Dispos. 27, 756-762.

Lamb, D.C., Kelly, D.E., Baldwin, B.C., Kelly, S.L., 2000. Differential inhibition of human CYP3A4 and Candida albicans CYP51 with azole antifungal agents. Chem. Biol. Interact. 125, 165-175.

Lamb, D.C., Kelly, D.E., Manning, N.J., Kaderbhai, M.A., Kelly, S.L., 1999a. Biodiversity of the P450 catalytic cycle: yeast cytochrome b5/NADH cytochrome b5 reductase complex efficiently drives the entire sterol 14-demethylation (CYP51) reaction. FEBS Lett. 462, 283-288. 
Lamb, D.C., Kelly, D.E., Manning, N.J., Kelly, S.L., 1997a. Reduced intracellular accumulation of azole antifungal results in resistance in Candida albicans isolate NCPF 3363. FEMS Microbiol. Lett. 147, 189-193.

Lamb, D.C., Kelly, D.E., Schunck, W.H., Shyadehi, A.Z., Akhtar, M., Lowe, D.J., Baldwin, B.C., Kelly, S.L., 1997b. The mutation T315A in Candida albicans sterol 14alpha-demethylase causes reduced enzyme activity and fluconazole resistance through reduced affinity. J. Biol. Chem. 272, 5682-5688.

Lamb, D.C., Kelly, D.E., Waterman, M.R., Stromstedt, M., Rozman, D., Kelly, S.L., 1999b. Characteristics of the heterologously expressed human lanosterol 14alpha-demethylase (other names: P45014DM, CYP51, P45051) and inhibition of the purified human and Candida albicans CYP51 with azole antifungal agents. Yeast 15, 755-763.

Lee, C.A., Kadwell, S.H., Kost, T.A., Serabjit-Singh, C.J., 1995. CYP3A4 expressed by insect cells infected with a recombinant baculovirus containing both CYP3A4 and human NADPHcytochrome $\mathrm{P} 450$ reductase is catalytically similar to human liver microsomal CYP3A4. Arch. Biochem. Biophys. 319, 157-167.

Lepesheva, G.I., Podust, L.M., Bellamine, A., Waterman, M.R., 2001. Folding requirements are different between sterol 14alphademethylase (CYP51) from Mycobacterium tuberculosis and human or fungal orthologs. J. Biol. Chem. 276, 28413-28420.

Lepesheva, G.I., Waterman, M.R., 2004. CYP51-the omnipotent P450. Mol. Cell. Endocrinol. 215, 165-170.

Nelson, D.R., 2006. http://www.drnelson.utmem.edu/ CytochromeP450.html.

Omura, T., Sato, R., 1964. The carbon monoxide-binding pigment of liver microsomes. I. Evidence for its hemoprotein nature. J. Biol. Chem. 239, 2370-2378.

Rozman, D., Waterman, M.R., 1998. Lanosterol 14alpha-demethylase (CYP51) and spermatogenesis. Drug Metab. Dispos. 26, 1199-1201.
Sutter, T.R., Sanglard, D., Loper, J.C., Sangard, D., 1990. Isolation and characterization of the alkane-inducible NADPHcytochrome P-450 oxidoreductase gene from Candida tropicalis. Identification of invariant residues within similar amino acid sequences of divergent flavoproteins. J. Biol. Chem. 265, 1642816436.

Trosken, E.R., Bittner, N., Volkel, W., 2005. Quantitation of 13 azole fungicides in wine samples by liquid chromatographytandem mass spectrometry. J. Chromatogr. A 1083, 113119.

Trosken, E.R., Scholz, K., Lutz, R.W., Volkel, W., Zarn, J.A., Lutz, W.K., 2004a. Comparative assessment of the inhibition of human recombinant CYP19 (aromatase) by azoles used in agriculture and as drugs for humans. Endocr. Res. 30, 387-394.

Trosken, E.R., Straube, E., Lutz, W.K., Volkel, W., Patten, C., 2004 b. Quantitation of lanosterol and its major metabolite FF-MAS in an inhibition assay of CYP51 by azoles with atmospheric pressure photoionization based LC-MS/MS. J. Am. Soc. Mass Spectrom. 15, 1216-1221.

Trzaskos, J.M., Henry, M.J., 1989. Comparative effects of the azolebased fungicide flusilazole on yeast and mammalian lanosterol 14 alpha-methyl demethylase. Antimicrob. Agents Chemother. 33, 1228-1231.

Vanden Bossche, H., Marichal, P., Gorrens, J., Bellens, D., Verhoeven, H., Coene, M.C., Lauwers, W., Janssen, P.A.J., 1987. Interaction of azole derivatives with cytochrome P-450 isozymes in yeast, fungi, plants and mammalian cells. Pestic. Sci. 21, 289306.

Vanden Bossche, H., Koymans, L., 1998. Cytochromes P450 in fungi. Mycoses 41 (Suppl. 1), 32-38.

Zarn, J.A., Bruschweiler, B.J., Schlatter, J.R., 2003. Azole fungicides affect mammalian steroidogenesis by inhibiting sterol 14 alpha-demethylase and aromatase. Environ. Health Perspect. 111, $255-262$. 